\title{
Treatment of Periodontitis and Endothelial Function
}

\author{
Maurizio S. Tonetti, D.M.D., Ph.D., Francesco D’Aiuto, D.M.D., Ph.D., \\ Luigi Nibali, D.M.D., Ph.D., Ann Donald, Clare Storry, B.Sc., \\ Mohamed Parkar, M.Phil., Jean Suvan, M.Sc., Aroon D. Hingorani, Ph.D., \\ Patrick Vallance, M.D., and John Deanfield, M.B., B.Chir.
}

ABSTRACT

\section{BACKGROUND}

Systemic inflammation may impair vascular function, and epidemiologic data suggest a possible link between periodontitis and cardiovascular disease.

\section{METHODS}

We randomly assigned 120 patients with severe periodontitis to community-based periodontal care (59 patients) or intensive periodontal treatment (61). Endothelial function, as assessed by measurement of the diameter of the brachial artery during flow (flow-mediated dilatation), and inflammatory biomarkers and markers of coagulation and endothelial activation were evaluated before treatment and 1, 7, 30, 60, and 180 days after treatment.

\section{RESULTS}

Twenty-four hours after treatment, flow-mediated dilatation was significantly lower in the intensive-treatment group than in the control-treatment group (absolute difference, $1.4 \%$; $95 \%$ confidence interval [CI], 0.5 to $2.3 ; \mathrm{P}=0.002$ ), and levels of C-reactive protein, interleukin-6, and the endothelial-activation markers soluble E-selectin and von Willebrand factor were significantly higher $(\mathrm{P}<0.05$ for all comparisons). However, flow-mediated dilatation was greater and the plasma levels of soluble E-selectin were lower in the intensive-treatment group than in the controltreatment group 60 days after therapy (absolute difference in flow-mediated dilatation, $0.9 \%$; $95 \% \mathrm{CI}, 0.1$ to $1.7 ; \mathrm{P}=0.02$ ) and 180 days after therapy (difference, $2.0 \%$; $95 \% \mathrm{CI}, 1.2$ to 2.8 ; $\mathrm{P}<0.001$ ). The degree of improvement was associated with improvement in measures of periodontal disease $(r=0.29$ by Spearman rank correlation, $\mathrm{P}=0.003)$. There were no serious adverse effects in either of the two groups, and no cardiovascular events occurred.

\section{CONCLUSIONS}

Intensive periodontal treatment resulted in acute, short-term systemic inflammation and endothelial dysfunction. However, 6 months after therapy, the benefits in oral health were associated with improvement in endothelial function.
From the Department of Oral Health and Diagnostic Sciences, University of Connecticut Health Center, Farmington (M.S.T.); and the Periodontology Unit, Eastman Dental Institute and Hospital, University College London (F.D., L.N., M.P., J.S.); Center for Clinical Pharmacology, University College London (A.D., A.D.H., P.V.); and the Vascular Physiology Unit, University College London and Great Ormond Street Hospital for Sick Children (A.D., C.S., J.D.) - all in London. Address reprint requests to Dr. Tonetti at maurizio. tonetti@ergoperio.eu.

N Engl J Med 2007;356:911-20.

Copyright @ 2007 Massachusetts Medical Society. 
Tा

NFLAMMATION PLAYS AN IMPORTANT ROLE in the pathogenesis of atherosclerosis, and low-grade chronic systemic inflammation has been shown to be linked to adverse cardiovascular outcomes. ${ }^{1}$ The nature and source of the inflammation, however, remain unclear. Periodontitis, a very common chronic infection of the tissue surrounding the teeth, is associated with elevated levels of C-reactive protein (CRP) and other inflammatory biomarkers. ${ }^{2-5}$ Cohort and casecontrol studies have shown that periodontitis is associated with endothelial dysfunction, ${ }^{6}$ atherosclerosis, ${ }^{7}$ and an increased risk of myocardial infarction and stroke. ${ }^{8}$ In experimental models, periodontal pathogens have been shown to promote platelet aggregation, ${ }^{9}$ foam-cell formation, ${ }^{10}$ and the development of atheromas. ${ }^{11,12}$ Clinical and epidemiologic studies suggesting a link between periodontitis and vascular disease, however, may be confounded by factors such as social status, smoking status, and other classic risk factors for atherosclerosis. ${ }^{13}$

Having shown in previous studies that intensive periodontal therapy results in local (periodontal) and systemic reductions in inflammation, ${ }^{14-16}$ we now report the results of a randomized, controlled study conducted to determine the effect of treatment of severe periodontitis on endothelial function. Endothelial dysfunction is thought to represent a common pathway through which a range of risk factors, including inflammation, may influence the long-term process of atherogenesis and acute inflammation may trigger acute cardiovascular events. ${ }^{17}$

\section{METHODS}

\section{STUDY DESIGN}

We conducted a parallel-group, single-blind, randomized, controlled trial to evaluate the effect of periodontal therapy on endothelial function over a 6-month period (Fig. 1). The primary outcome was the between-group difference in flow-mediated dilatation during the study. Consecutive patients referred to the Eastman Dental Hospital in London for periodontal therapy were invited to participate if they had severe generalized periodontitis (probing pocket depths of $>6 \mathrm{~mm}$ and marginal alveolar bone loss of $>30 \%$ ) with $50 \%$ or more of their teeth affected. ${ }^{14}$ Exclusion criteria were the presence of systemic disease (e.g., diabetes mellitus or cardiovascular, kidney, liver, or lung disease), a history or the presence of any other acute or chronic infections, as assessed on clinical examination and routine laboratory testing, and systemic antibiotic treatment within the previous 3 months or any other, regular medication. All patients gave written informed consent. The study was approved by the joint Eastman and University College Hospitals ethics committee.

A baseline periodontal examination was performed, and full medical and dental histories were collected by a single examiner. Blood pressure was measured in triplicate (HEM-705CP, Omron), and the average of the readings was recorded. Patients were randomly assigned with the use of a computer-generated table to receive intensive periodontal treatment (the intensive-treatment group) or community-based periodontal care (the control-treatment group). A balanced, permutedblock approach (in blocks of four patients) was used to prepare the randomization tables. To prevent an imbalance between the two groups with respect to smoking status, sex, age, and severity of periodontitis, restricted randomization (minimization) ${ }^{18}$ was performed by the study registrar. Treatment assignments were concealed in opaque envelopes and revealed to the therapist only on the day the treatment was administered. Patients underwent dental examinations and vascular studies at 1, 7, 30, 60, and 180 days after the administration of the therapy.

\section{PERIODONTAL EXAMINATION AND THERAPY}

Periodontal data were recorded by a single trained dental examiner, who was unaware of the treatment assignments, at baseline and 2 months and 6 months after administration of the therapy. The data included the periodontal pocket depth and the recession of the gingival margin relative to the cementoenamel junction at six sites per tooth. The presence or absence of supragingival dental plaque and gingival bleeding on probing was also recorded. The averaged whole-mouth number of periodontal lesions (probing depth, $>4 \mathrm{~mm}$ ), the score for full-mouth gingival bleeding on probing (the number of sites with gingival bleeding on probing divided by the total number of sites per mouth, multiplied by 100), and the score for full-mouth plaque (the number of sites with detectable supragingival dental plaque divided by the total number of sites per mouth, multiplied by 100) were calculated for each patient and were compared between the two groups. ${ }^{14}$ 
Figure 1. Study Design from Screening to Completion of the Trial.

After a baseline visit, eligible patients were randomly assigned to either community-based (control) or intensive periodontal therapy. Patients were reexamined 1 and 7 days and 1,2, and 6 months after the administration of the therapy. Endothelial function was assessed, blood samples were obtained, and periodontal clinical measurements were performed at the points indicated.

All patients were given instructions in basic oral hygiene. Patients in the control-treatment group underwent a standard cycle of supragingival mechanical scaling and polishing. Patients in the intensive-treatment group underwent the adjunctive full-mouth intensive removal of subgingival dental plaque biofilms with the use of scaling and root planing after the administration of local anesthesia; teeth that could not be saved were extracted, and microspheres of minocycline (Arestin, OraPharma) were delivered locally into the periodontal pockets. ${ }^{15}$ Patients in whom periodontal disease progressed received immediate care from a specialist and were withdrawn from the study.

\section{VASCULAR FUNCTION}

A range of measures of endothelial function, including vasomotion and circulating markers of coagulation and adhesion status, were studied by members of the study staff who were unaware of the treatment assignments. Endothelium-dependent vasodilatation of the brachial artery (the primary outcome) was assessed by means of ultrasound imaging (Acuson XP 128/10, Siemens) with the use of a $7-\mathrm{MHz}$ linear probe and automated vessel-diameter measurements (Brachial Tools, version 3.2.6, Medical Imaging Applications). The studies were performed by a single examiner who acquired the images of the brachial artery in the morning, while patients were fasting, in a temperature-controlled room after 10 minutes of rest. ${ }^{19}$ The brachial artery was imaged above the antecubital fossa continuously for 1 minute at baseline and again after inflation (pressure, $250 \mathrm{~mm} \mathrm{Hg}$ for 5 minutes) and deflation of a sphygmomanometer cuff placed on the forearm. R-wave-triggered end-diastolic images of the vessel diameter were digitized and recorded at 3-second intervals throughout the procedure and were subsequently analyzed offline with the use of dedicated edgedetection software (Brachial Tools, Medical Imaging Applications). Dilatation was quantified as

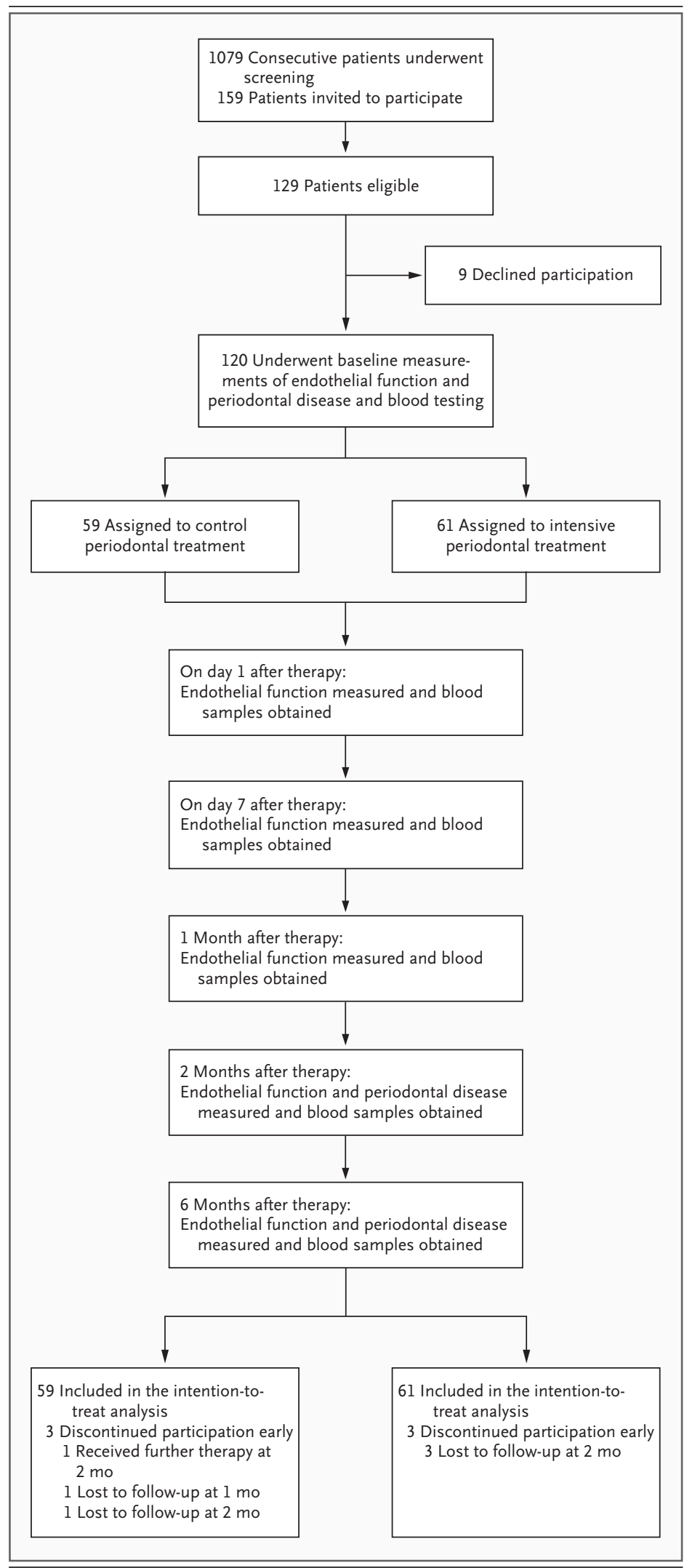


the change, expressed as a percentage, from baseline to the peak diameter, between 45 and 75 seconds after release of the blood-pressure cuff (averaged over three frames). After 10 minutes of rest, endothelium-dependent dilatation was measured after sublingual administration of $25 \mu \mathrm{g}$ of nitroglycerin, according to the same recording protocol.

Doppler-derived flow measurements (performed with the use of a pulse-wave Doppler signal at a $70^{\circ}$ angle) were also obtained continuously. The increase in blood flow after release of the bloodpressure cuff was expressed as the reactive-hyperemia ratio (the value for reactive hyperemia divided by the baseline value for blood flow in the forearm). Duplicate analyses were performed by two observers who were unaware of the treatment assignments, the clinical details, and the stage of the experiment. The correlation between the observers was greater than 0.90 , with a betweenobserver coefficient of variation of less than $5 \%$ for both vessel diameter and flow-mediated dilatation.

\section{LABORATORY ASSESSMENTS}

Serum and plasma samples were obtained from the patients and were immediately processed and stored at $-70^{\circ} \mathrm{C}$ until analysis by laboratory staff who were unaware of the treatment assignments and vascular findings. Full blood counts and measurements of lipid and glucose levels were performed by standard biochemical testing. Serum levels of CRP were measured with an immunoturbidimetric, high-sensitivity assay (Tina-quant CRP immunoturbidimetric assay performed on a Cobas Integra analyzer, Roche Diagnostics). Serum levels of interleukin- 6 and soluble E-selectin were measured by enzyme-linked immunosorbent assay (ELISA) (Quantikine HS, R\&D Systems), and commercial, high sensitivity ELISAs were used to measure plasma levels of tissue plasminogen activator (t-PA) and plasminogen-activator inhibitor type 1 (PAI-1) (TintElize and Biopool, respectively, Trinity Biotech) and von Willebrand factor (CBA ELISA, Technoclone).

\section{STATISTICAL ANALYSIS}

We calculated that a minimum of 120 patients would need to be enrolled to detect a $1 \%$ difference in flow-mediated dilatation between the two treatment groups, with a standard deviation of the mean difference of $1.67 \%$ at a two-sided alpha level of $5 \%$ and $90 \%$ power. Data are reported as means and $95 \%$ confidence intervals (CIs), unless otherwise specified. All analyses were based on the intention-to-treat principle and were performed by investigators who were unaware of the treatment assignments. We performed a repeated-measures analysis of variance to determine differences in flow-mediated dilatation (the primary outcome) and all secondary and other outcomes between the two groups and over time, using a conservative F-test for the interaction between time and treatment group (SPSS software, version 13). The Greenhouse-Geisser correction for the F test was used to adjust the degrees of freedom for deviation from sphericity (one of the assumptions of repeated-measures analysis of variance [ANOVA]). Logarithmic transformation of the data was performed when appropriate, and post hoc Fisher's paired and unpaired tests of least-significant difference were performed and interpreted with the use of the Bonferroni-Holm adjustment for multiple comparisons.

Secondary outcomes were the between-group differences in the levels of inflammatory markers and markers of coagulation and endothelial activation. Other outcomes included differences in sublingual nitroglycerin-mediated dilatation, routine laboratory measurements, clinical periodontal measurements, and arterial blood pressure. Age, sex, smoking status, race or ethnic group, body-mass index, vessel diameter for flow-mediated dilatation and nitroglycerin-mediated dilatation, and periodontal diagnosis were included in all models as covariates. Race or ethnic group was self-reported. A post hoc correlation analysis (by the Spearman rank-correlation method) was performed to evaluate the relationship between the change in flow-mediated dilatation from baseline to 6 months after therapy and changes in the number of periodontal lesions and gingival bleeding sites from baseline to 6 months. Differences between categorical variables were calculated with the use of the chi-square test. A two-sided P value of less than 0.05 was considered to indicate statistical significance.

RESULTS

During 1 year (September 2003 to September 2004), 159 of the 1079 patients examined met the inclusion criteria for severe generalized periodontal disease. Of these 159 patients, 129 met all the eligibil- 
ity criteria, but 9 declined to participate. A total of ed the trial, attending all study visits (to the end 120 patients underwent randomization, of whom of the trial, in March 2005). Reasons for withdraw114 (56 assigned to the control-treatment group al are shown in Figure 1. One patient in the controland 58 to the intensive-treatment group) complet- treatment group had clinical signs of periodontal

\begin{tabular}{|c|c|c|}
\hline Characteristic & $\begin{array}{l}\text { Control-Treatment Group } \\
\qquad(\mathrm{N}=59)\end{array}$ & $\begin{array}{l}\text { Intensive-Treatment Group } \\
\qquad(\mathrm{N}=61)\end{array}$ \\
\hline Age $-y r$ & $47.8 \pm 6.3$ & $47.7 \pm 7.9$ \\
\hline Male sex - no. (\%) & $30(51)$ & $30(49)$ \\
\hline \multicolumn{3}{|l|}{ Smoking status — no. (\%) } \\
\hline Never smoked & $21(36)$ & $24(39)$ \\
\hline Former smoker & $18(31)$ & $19(31)$ \\
\hline Current smoker & $20(34)$ & $18(30)$ \\
\hline Family history of cardiovascular disease - no. (\%) & $40(68)$ & $38(62)$ \\
\hline \multicolumn{3}{|l|}{ Race or ethnic group — no. (\%) $\dagger$} \\
\hline White & $41(69)$ & $41(68)$ \\
\hline Black & $6(10)$ & $8(13)$ \\
\hline Asian & $10(17)$ & $8(13)$ \\
\hline Other & $2(3)$ & $4(7)$ \\
\hline Body-mass indext & $27.3 \pm 5.4$ & $27.2 \pm 5.0$ \\
\hline \multicolumn{3}{|l|}{ Blood pressure $-\mathrm{mm} \mathrm{Hg}$} \\
\hline Systolic & $124.5 \pm 17.4$ & $125.6 \pm 15.9$ \\
\hline Diastolic & $79.2 \pm 11.1$ & $80.5 \pm 11.4$ \\
\hline Brachial-artery diameter - mm & $3.6 \pm 0.6$ & $3.7 \pm 0.8$ \\
\hline Reactive hyperemia ratio $\mathbb{S}$ & $8.9 \pm 4.1$ & $8.8 \pm 4.2$ \\
\hline Flow-mediated dilatation — \% & $6.5 \pm 2.6$ & $7.1 \pm 4.2$ \\
\hline Nitroglycerin-mediated dilatation — \% & $17.9 \pm 6.9$ & $17.9 \pm 6.5$ \\
\hline $\mathrm{CRP}-\mathrm{mg} / \mathrm{liter}$ & $3.8 \pm 5.3$ & $2.5 \pm 2.7$ \\
\hline Interleukin-6 - pg/ml & $2.1 \pm 3.9$ & $2.4 \pm 5.4$ \\
\hline Soluble E-selectin — ng/ml & $20.3 \pm 13.6$ & $19.6 \pm 14.0$ \\
\hline $\mathrm{t}-\mathrm{PA}-\mathrm{ng} / \mathrm{ml}$ & $4.5 \pm 0.6$ & $3.2 \pm 0.4$ \\
\hline PAI-1 — ng/ml & $21.39 \pm 1.8$ & $21.5 \pm 1.5$ \\
\hline Von Willebrand factor — IU/ml & $0.87 \pm 0.16$ & $0.90 \pm 0.19$ \\
\hline Leukocyte count $-\times 10^{-9} /$ liter & $7.1 \pm 2.0$ & $6.4 \pm 1.6$ \\
\hline Cholesterol $-\mathrm{mmol} / \mathrm{liter}$ & $5.3 \pm 1.2$ & $5.3 \pm 1.0$ \\
\hline High-density lipoprotein & $1.5 \pm 0.4$ & $1.5 \pm 0.4$ \\
\hline Low-density lipoprotein & $3.2 \pm 1.0$ & $3.1 \pm 0.9$ \\
\hline Glucose $-\mathrm{mmol} /$ liter & $5.1 \pm 0.6$ & $5.1 \pm 0.8$ \\
\hline Triglycerides - $\mathrm{mmol} /$ liter & $1.5 \pm 1.5$ & $1.4 \pm 1.0$ \\
\hline
\end{tabular}

* Plus-minus values are means \pm SE. To convert values for cholesterol to milligrams per deciliter, divide by 0.02586 . To convert values for glucose to milligrams per deciliter, divide by 0.05551 . To convert values for triglycerides to milligrams per deciliter, divide by 0.01129 . CRP denotes C-reactive protein, t-PA tissue plasminogen activator, and PAI-1 plasminogen-activator inhibitor type 1 .

$\uparrow$ Race was self-reported.

Body-mass index is defined as the weight in kilograms divided by the square of the height in meters.

$\int$ The reactive hyperemia ratio is the value for reactive hyperemia divided by the baseline value of blood flow in the forearm after release of the blood-pressure cuff.

I The total numbers of patients for the analysis of sublingual nitroglycerin-mediated dilatation were 47 in the controltreatment group and 51 in the intensive-treatment group. 
disease progression and was withdrawn early. There were no major adverse events in either of the two groups (Table S1 in the Supplementary Appendix, available with the full text of this article at www. nejm.org).

\section{PATIENT CHARACTERISTICS AND CARDIOVASCULAR RISK FACTORS}

The baseline characteristics of the patients in the control-treatment group and the intensive-treatment group were similar (Table 1). There were no significant differences between the two groups in diet, medication regimen, smoking status, lipid levels, body-mass index, and blood glucose levels (Table S2 in the Supplementary Appendix). Systolic blood pressure was significantly higher among patients in the intensive-treatment group 24 hours after the therapy was administered than among those in the control-treatment group (5.0 \pm 1.7 $\mathrm{mm} \mathrm{Hg}$; 95\% CI, 1.7 to 8.4; $\mathrm{P}=0.004)$. No other significant differences were subsequently observed.

\section{PERIODONTAL OUTCOMES}

Repeated-measures ANOVA of the periodontal outcomes showed a significant interaction between treatment and time $(\mathrm{P}<0.001)$. As compared with the control-treatment group, the intensive-treatment group had lower scores for plaque 2 months after therapy (absolute difference, 27\%; 95\% CI, 21 to 34; $\mathrm{P}<0.001$ ) and 6 months after therapy (absolute difference, $22 \%$; $95 \%$ CI, 15 to $30 ; \mathrm{P}<0.001$ ) (Table 2). Similarly, patients in the intensive-treatment group had lower scores for gingival bleeding than those in the control-treatment group, 2 months after therapy (absolute difference, 39\%;
95\% CI, 33 to 45; $\mathrm{P}<0.001$ ) and 6 months after therapy (absolute difference, 39\%; 95\% CI, 32 to 45; $\mathrm{P}<0.001)$. Patients in the intensive-treatment group had fewer periodontal lesions 2 months after therapy (difference between groups, 61; 95\% CI, 53 to 69; $\mathrm{P}<0.001$ ) and 6 months after therapy (difference between groups, 66 ; $95 \% \mathrm{CI}$, 56 to $74 ; \mathrm{P}<0.001$ ) (Table 2). Among patients in the intensive-treatment group, an average of two teeth (95\% CI, 0 to 2) were extracted, whereas no extractions were performed in the control-treatment group.

\section{VASCULAR FUNCTION}

Repeated-measures analysis of variance of flowmediated dilatation showed a significant interaction between treatment and time $(\mathrm{P}<0.001)$ (Fig. 2). Twenty-four hours after the administration of the assigned therapy, flow-mediated dilatation was lower in the intensive-treatment group than in the control-treatment group (absolute difference, $1.4 \%$; $95 \% \mathrm{CI}, 0.5$ to 2.3 ; $\mathrm{P}=0.002)$. However, flowmediated dilatation was higher in the intensivetreatment group than in the control-treatment group 2 months after therapy (absolute difference, $0.9 \% ; 95 \% \mathrm{CI}, 0.1$ to $1.7 ; \mathrm{P}=0.02$ ) and 6 months after therapy (absolute difference, $2.0 \%$; $95 \% \mathrm{CI}$, 1.2 to 2.8 ; $\mathrm{P}<0.001$ ) (Table S2 in the Supplementary Appendix).

There was a significant effect of time on nitroglycerin-mediated dilatation according to repeated-measures analysis of variance $(\mathrm{P}=0.008)$, but there was no interaction between treatment and time $(\mathrm{P}=0.49)$, suggesting that the response to nitroglycerin changed in the two groups during the study period (Fig. 2). The differences between

\begin{tabular}{|c|c|c|c|c|c|c|}
\hline \multirow[t]{2}{*}{ Variable } & \multicolumn{3}{|c|}{ Control-Treatment Group } & \multicolumn{3}{|c|}{ Intensive-Treatment Group } \\
\hline & Baseline & 2 Months & 6 Months & Baseline & 2 Months & 6 Months \\
\hline Total no. of teeth & $27 \pm 3$ & $27 \pm 3$ & $27 \pm 3$ & $27 \pm 3$ & $25 \pm 4 \dagger+$ & $25 \pm 4 \dagger \div$ \\
\hline No. of lesions (periodontal pockets) & $84 \pm 26$ & $81 \pm 27$ & $80 \pm 31$ & $82 \pm 27$ & $20 \pm 15 \dagger+$ & $14 \pm 12 \dagger$ \\
\hline Sites with detectable plaque (\%)』 & $63 \pm 21$ & $42 \pm 22 \dagger$ & $47 \pm 22 †$ & $66 \pm 20$ & $15 \pm 10 \dagger+$ & $25 \pm 18 \dagger$ \\
\hline Sites with gingival bleeding (\%) & $68 \pm 17$ & $63 \pm 19 \|$ & $65 \pm 20 \|$ & $66 \pm 18$ & $24 \pm 13 \uparrow+$ & $26 \pm 16+t$ \\
\hline \multicolumn{7}{|c|}{$\begin{array}{l}\text { Plus-minus values are means } \pm \text { SD. } \\
P<0.001 \text { for the comparison with baseline. } \\
P<0.001 \text { for the comparison with the standard-treatment group. } \\
\text { Scores for full-mouth gingival bleeding were calculated for each patient as the number of sites with gingival bleeding on probing divided by } \\
\text { the total number of sites per mouth, multiplied by } 100 \text {. } \\
\text { Scores for full-mouth plaque were calculated for each patient as the number of sites with detectable plaque divided by the total number of } \\
\text { sites per mouth, multiplied by } 100 \text {. } \\
P<0.05 \text { for the comparison with baseline. }\end{array}$} \\
\hline
\end{tabular}


the two groups in flow-mediated dilatation and sublingual nitroglycerin-mediated dilatation were not correlated with differences in the baseline vessel diameter or the reactive hyperemia ratio (data not shown).

\section{MARKERS OF INFLAMMATION, COAGULATION, AND ADHESION}

Repeated-measures analysis of variance showed a significant interaction between treatment and time for most of the secondary biomarkers (neutrophil count, levels of CRP, interleukin-6 [ $\mathrm{P}<0.001]$, von Willebrand factor $[\mathrm{P}=0.009]$, soluble E-selectin $[\mathrm{P}=0.002]$, PAI- $1[\mathrm{P}=0.04]$, and $\mathrm{t}-\mathrm{PA}[\mathrm{P}=0.87])$. Twenty-four hours after therapy, levels of interleukin- 6 were higher in the intensive-treatment group than in the control-treatment group (difference, 8.1 pg per milliliter; 95\% CI, 6.1 to 10.1 ; $\mathrm{P}<0.001$ ), as were the levels of CRP (difference, 13.7 mg per liter; $95 \%$ CI, 10.4 to $17.0 ; \mathrm{P}<0.001$ ), PAI-1 (difference, $5.1 \mathrm{ng}$ per milliliter; 95\% CI, 1.0 to $9.8 ; \mathrm{P}=0.02$ ), soluble E-selectin (difference, 1.8 ng per milliliter; $95 \% \mathrm{CI}, 1.1$ to $2.8 ; \mathrm{P}=0.02$ ), and von Willebrand factor (difference, $1.2 \mathrm{ng}$ per milliliter; 95\% CI, 1.1 to $1.3 ; \mathrm{P}=0.001$ ) and the neutrophil count (difference, $1.7 \times 10^{9}$ cells per liter; $95 \% \mathrm{CI}, 1.2$ to 2.2 ; $\mathrm{P}<0.001$ ) (Fig. 3).

Levels of soluble E-selectin were lower in the intensive-treatment group than in the controltreatment group 2 months after therapy (difference, 2.7 ng per milliliter; 95\% CI, 1.4 to 8.6; $\mathrm{P}=0.02$ ) and 6 months after therapy (difference, 2.8 ng per milliliter; $95 \%$ CI, 1.3 to 8.4 ; $\mathrm{P}=0.03$ ) (Fig. 3). Between-group differences in serum levels of CRP did not reach statistical significance at 2 months (1.4 mg per liter; 95\% CI, -1.0 to 1.8; $\mathrm{P}=0.09$ ) or at 6 months (1.4 mg per liter; 95\% CI, -1.0 to $2.0 ; \mathrm{P}=0.07)$.

\section{DETERMINANTS OF VASCULAR FUNCTION}

There was a significant correlation between the change in flow-mediated dilatation 6 months after periodontal therapy and changes in clinical periodontal outcomes in response to therapy. Improvement in endothelial function was related to a reduction in the number of periodontal lesions $(r=0.30$ by Spearman rank correlation, $\mathrm{P}=0.002$ ) and to a reduction in scores for full mouth bleeding ( $\mathrm{r}=0.29$ by Spearman rank correlation, $\mathrm{P}=0.003$ ) (Fig. $\mathrm{S} 1$ in the Supplementary Appendix).

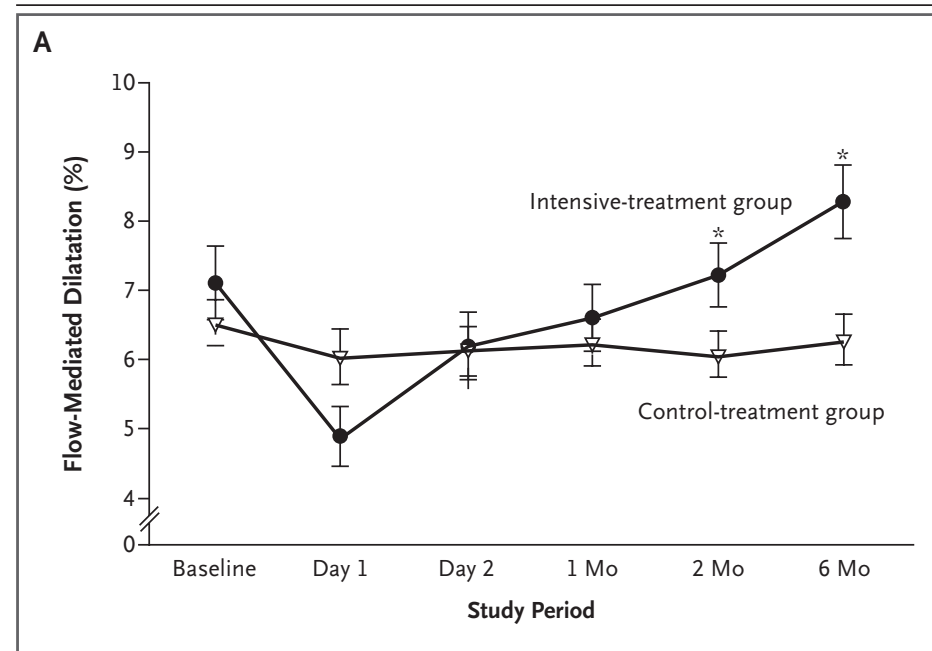

B

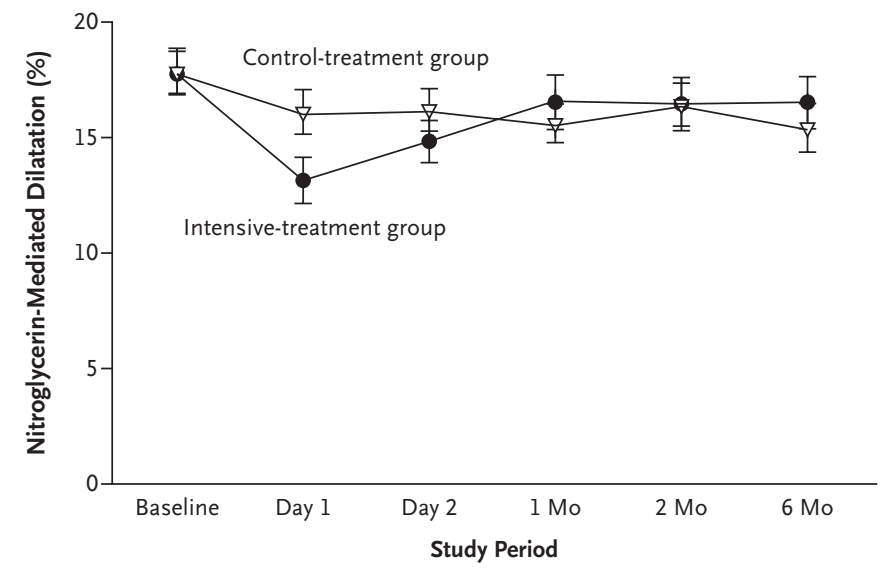

Figure 2. Flow-Mediated Dilatation and Nitroglycerin-Mediated Dilatation during the 6-Month Study Period.

I bars represent SE. Data are for the 61 patients in the intensive-treatment group and the 59 patients in the control-treatment group. Asterisks indicate significant between-group differences $(P<0.05)$. $P$ values were calculated by repeated-measures analysis of variance with the use of the BonferroniHolm adjustment for multiple comparisons. 


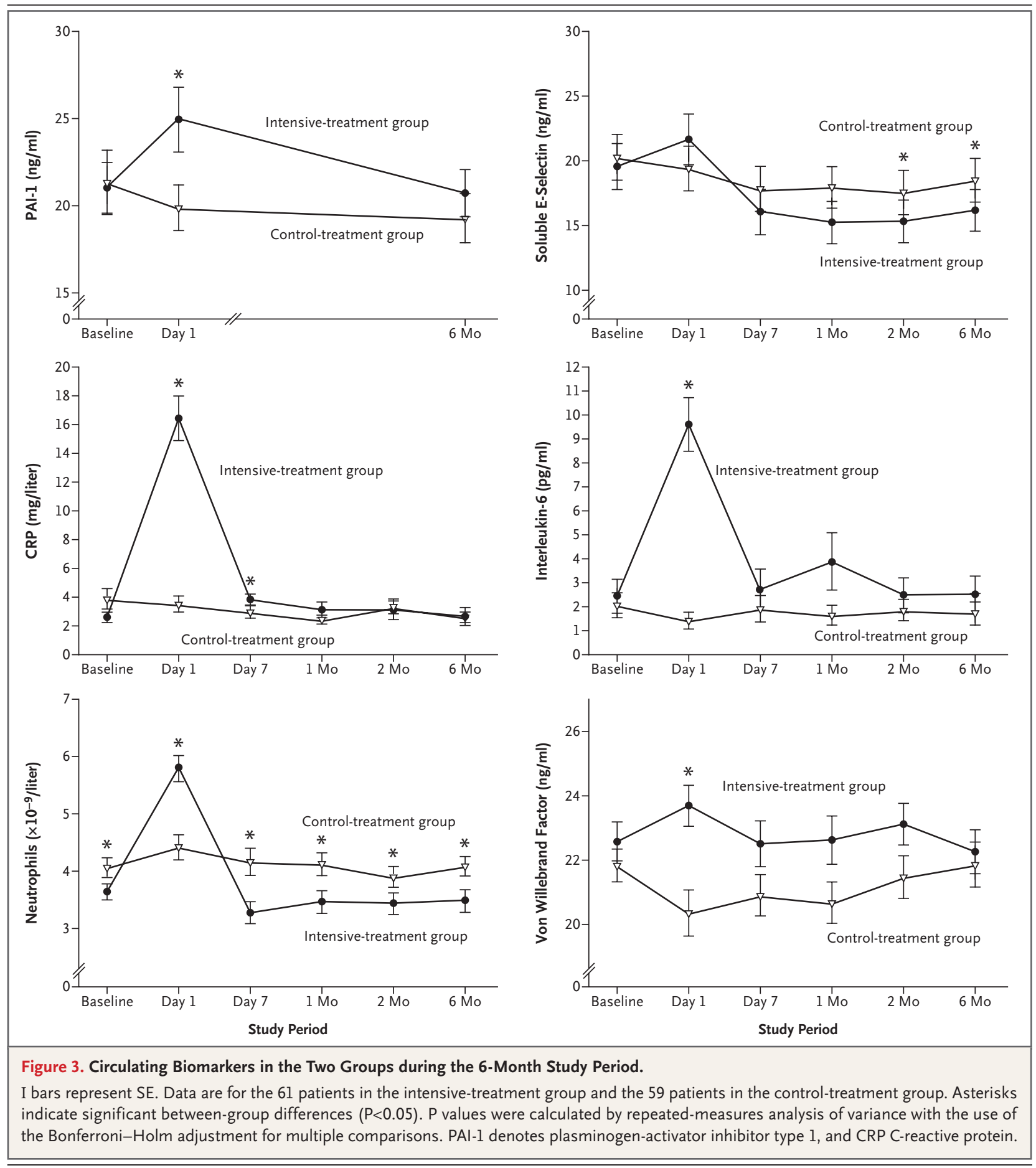

ed with reduced indexes of periodontal disease severity and significantly better endothelial function.

Periodontitis is associated with increased levels of markers of inflammation, including CRP, fibrinogen, and cytokines. ${ }^{2-5,20-22}$ Emerging evidence suggests that periodontitis may have a role in chronic infection, the associated inflammatory responses in atherosclerosis and its complications, or both, and experimental and clinical studies have indicated a potentially deleterious effect of periodontitis. Periodontal pathogens in vitro can promote platelet aggregation ${ }^{9}$ and foam-cell formation. ${ }^{10}$ Porphyromonas gingivalis, an important periodontal pathogen, increased cholesterol levels and 
the formation of atheromas in inoculated apolipoprotein-E knockout mice. ${ }^{11,12}$ In clinical studies, the presence of periodontal bacteria ${ }^{23}$ and periodontitis ${ }^{7,23}$ has been associated with increased thickness of the carotid intima media. Furthermore, case-control and cross-sectional investigations have suggested the possibility of a link to cardiovascular outcomes. ${ }^{8}$ Our prospective, randomized study showed that the treatment of periodontitis is associated with alterations in endothelial function.

Endothelial dysfunction occurs early in the pathogenesis of arterial disease, in response to a wide range of risk factors that have been shown to predict cardiovascular events in epidemiologic studies. ${ }^{24}$ Furthermore, in the clinical phase of atherosclerosis, endothelial dysfunction is associated with an adverse prognosis. ${ }^{25,26}$ We chose flow-mediated dilatation of the brachial artery as our primary end point and as an index of endothelial function. Previous work in our laboratory has led us to adopt a standard protocol for the measurement and analysis of flow-mediated dilatation that minimizes the variability in this end point, and this protocol was used in our trial. Flow-mediated dilatation reflects nitric oxidemediated vasomotor function in part, ${ }^{27}$ and may also provide an index of the effects of nitric oxide on coagulation, cell adhesion, and cell proliferation. ${ }^{28-30}$ We have previously shown that the response is reduced after an extrinsic experimental inflammatory stimulus (e.g., vaccination with Salmonella typhi) ${ }^{31}$ and acute childhood infection. ${ }^{19}$

The mechanism by which periodontitis might affect endothelial function remains uncertain. Periodontitis involves bacterial infection with a range of gram-negative bacteria that invade superficial and deeper gingival tissues, depending on the severity. ${ }^{32}$ It is possible, therefore, that these pathogens or their products could affect endothelial function directly, since even brushing the teeth or chewing can result in an ephemeral bacteremia. ${ }^{33}$ In cell cultures, P. gingivalis has been shown to invade endothelial cells, ${ }^{34}$ and periodontal pathogens have been identified in carotid atheromatous plaques in patients undergoing endarterectomy. ${ }^{35}$ Alternatively, these pathogens might act as a trigger for a systemic inflammatory response that, in turn, might have detrimental effects on the vascular wall. The emerging evidence that other inflammatory disorders, such as systemic lupus erythematosus ${ }^{36}$ and rheumatoid arthritis, ${ }^{37}$ are associated with increased cardiovas- cular risk supports this as a plausible mechanism. In our study, during the acute response to periodontal therapy, there was a broad concordance between markers of inflammation and endothelial function, with a sharp rise in CRP and interleukin-6 levels in association with a substantial impairment in flow-mediated dilatation and increased PAI-1 and soluble E-selectin levels. CRP levels and neutrophil counts were decreased 6 months after the administration of the therapy in both treatment groups, but this effect was not associated with the difference in flow-mediated dilatation between the two groups. These changes may have occurred because CRP and the other markers involved may not adequately reflect the relevant inflammatory pathways or because the long-term effects are independent of a systemic inflammatory response. We studied well-characterized patients with severe periodontal disease who did not have systemic disease but who were at high risk for cardiovascular events. This may explain the relatively high levels of CRP measured at baseline and at the end of the 6-month study period.

It is likely that periodontitis of the severity seen in the patients in this study affects about 0.5 to $1.0 \%$ of the adult population in the United States - about 3 million people in all. ${ }^{38}$ An estimated 21 to $80 \%$ of U.S. adults have some form of periodontal disease, but it remains uncertain whether those with less severe disease would have improvements in vascular function that would be similar to the improvements in our study population. Further studies are required to determine whether the treatment of severe periodontitis could contribute to the prevention of atherosclerosis and cardiovascular events in adults.

Supported by grants from the University College London Hospital Research and Development Directorate, the British Heart Foundation, the European Research Group on Periodontology, the Periodontology Research Fund of the Eastman Dental Institute, Johnson \& Johnson (an unrestricted grant), the Coronary Artery Disease Research Association (to Ms. Donald), the British Heart Foundation (to Drs. Deanfield and Hingorani), the European Social Fund and Il Circolo (to Dr. D'Aiuto), and the Italian Society of Periodontology (to Dr. Nibali).

Dr. Tonetti reports serving on the advisory boards of OraPharma (Johnson \& Johnson) and ITI Biologics, which is financially supported by Straumann, and receiving consulting fees from Thommen Medical; and Dr. Vallance reports that he is now senior vice president for drug discovery at GlaxoSmithKline. No other potential conflict of interest relevant to this article was reported.

We thank the clinical staff of the Periodontology Unit at the Eastman Dental Institute and Hospital, University College London, for their kind assistance; Dr. U. Darbar and Mr. K. Patel for invaluable help with recruitment; and D. Moskal and B. Hirani for their dedication and assistance. 
REFERENCES

1. Libby P, Ridker PM, Maseri A. Inflammation and atherosclerosis. Circulation 2002;105:1135-43.

2. Loos BG, Craandijk J, Hoek FJ, Wertheim-van Dillen PM, van der Velden U. Elevation of systemic markers related to cardiovascular diseases in the peripheral blood of periodontitis patients. J Periodontol 2000;71:1528-34.

3. Noack B, Genco RJ, Trevisan M, Grossi S, Zambon JJ, De Nardin E. Periodontal infections contribute to elevated systemic C-reactive protein level. J Periodontol 2001; 72:1221-7.

4. Slade GD, Offenbacher S, Beck JD, Heiss G, Pankow JS. Acute-phase inflammatory response to periodontal disease in the US population. J Dent Res 2000;79:4957.

5. Slade GD, Ghezzi EM, Heiss G, Beck JD, Riche E, Offenbacher S. Relationship between periodontal disease and C-reactive protein among adults in the Atherosclerosis Risk in Communities study. Arch Intern Med 2003;163:1172-9.

6. Amar S, Gokce N, Morgan S, Loukideli M, Van Dyke TE, Vita JA. Periodontal disease is associated with brachial artery endothelial dysfunction and systemic inflammation. Arterioscler Thromb Vasc Biol 2003;23:1245-9.

7. Beck JD, Elter JR, Heiss G, Couper D, Mauriello SM, Offenbacher S. Relationship of periodontal disease to carotid artery intima-media wall thickness: the Atherosclerosis Risk in Communities (ARIC) study. Arterioscler Thromb Vasc Biol 2001; 21:1816-22.

8. Scannapieco FA, Bush RB, Paju S. Associations between periodontal disease and risk for atherosclerosis, cardiovascular disease, and stroke: a systematic review. Ann Periodontol 2003;8:38-53.

9. Herzberg MC, Weyer MW. Dental plaque, platelets, and cardiovascular diseases. Ann Periodontol 1998;3:151-60.

10. Qi M, Miyakawa H, Kuramitsu HK. Porphyromonas gingivalis induces murine macrophage foam cell formation. Microb Pathog 2003;35:259-67.

11. Lalla E, Lamster IB, Hofmann MA, et al. Oral infection with a periodontal pathogen accelerates early atherosclerosis in apolipoprotein E-null mice. Arterioscler Thromb Vasc Biol 2003;23:1405-11.

12. Li L, Messas E, Batista EL Jr, Levine RA, Amar S. Porphyromonas gingivalis infection accelerates the progression of atherosclerosis in a heterozygous apolipoprotein E-deficient murine model. Circulation
2002;105:861-7. [Erratum, Circulation 2002; 105:1617.]

13. Hujoel PP, Drangsholt M, Spiekerman C, DeRouen TA. Periodontal disease and coronary heart disease risk. JAMA 2000 ; 284:1406-10.

14. D'Aiuto F, Parkar M, Andreou G, et al Periodontitis and systemic inflammation: control of the local infection is associated with a reduction in serum inflammatory markers. J Dent Res 2004;83:156-60.

15. D'Aiuto F, Nibali L, Parkar M, Suvan J, Tonetti MS. Short-term effects of intensive periodontal therapy on serum inflammatory markers and cholesterol. J Dent Res 2005;84:269-73.

16. D'Aiuto F, Parkar M, Nibali L, Suvan J, Lessem J, Tonetti MS. Periodontal infections cause changes in traditional and nove cardiovascular risk factors: results from a randomized controlled clinical trial. Am Heart J 2006;151:977-84.

17. Smeeth L, Thomas SL, Hall AJ, Hubbard R, Farrington P, Vallance P. Risk of myocardial infarction and stroke after acute infection or vaccination. N Engl J Med 2004;351:2611-8.

18. Altman DG, Bland JM. Treatment allocation by minimisation. BMJ 2005;330 843.

19. Charakida M, Donald AE, Terese M, et al. Endothelial dysfunction in childhood infection. Circulation 2005;111:1660-5.

20. Ebersole JL, Machen RL, Steffen MJ Willmann DE. Systemic acute-phase reactants, C-reactive protein and haptoglobin in adult periodontitis. Clin Exp Immuno 1997;107:347-52.

21. Kweider M, Lowe GD, Murray GD Kinane DF, McGowan DA. Dental disease, fibrinogen and white cell count: links with myocardial infarction? Scott Med 1993;38:73-4.

22. Schwahn C, Volzke H, Robinson DM et al. Periodontal disease, but not edentulism, is independently associated with increased plasma fibrinogen levels: results from a population-based study. Thromb Haemost 2004;92:244-52.

23. Desvarieux M, Demmer RT, Rundek $\mathrm{T}$, et al. Periodontal microbiota and carotid intima-media thickness: the Oral Infections and Vascular Disease Epidemiology Study (INVEST). Circulation 2005;111:576-82.

24. Lerman A, Zeiher AM. Endothelial function: cardiac events. Circulation 2005; 111:363-8.

25. Fichtlscherer S, Breuer S, Zeiher AM Prognostic value of systemic endothelial dysfunction in patients with acute coro- nary syndromes: further evidence for the existence of the "vulnerable" patient. Circulation 2004;110:1926-32.

26. Halcox JP, Schenke WH, Zalos G, et al. Prognostic value of coronary vascular endothelial dysfunction. Circulation 2002; 106:653-8.

27. Brunner H, Cockcroft JR, Deanfield J, et al. Endothelial function and dysfunction. Part II: association with cardiovascular risk factors and diseases. A statement by the Working Group on Endothelins and Endothelial Factors of the European Society of Hypertension. J Hypertens 2005; 23:233-46.

28. Moncada S. Nitric oxide in the vasculature: physiology and pathophysiology. Ann N Y Acad Sci 1997;811:60-7.

29. Ganz P, Vita JA. Testing endothelial vasomotor function: nitric oxide, a multipotent molecule. Circulation 2003;108: 2049-53.

30. Quyyumi AA, Dakak N, Andrews NP, et al. Nitric oxide activity in the human coronary circulation: impact of risk factors for coronary atherosclerosis. J Clin Invest 1995;95:1747-55.

31. Hingorani AD, Cross J, Kharbanda $\mathrm{RK}$, et al. Acute systemic inflammation impairs endothelium-dependent dilatation in humans. Circulation 2000;102:994-9.

32. Pihlstrom BL, Michalowicz BS, Johnson NW. Periodontal diseases. Lancet 2005;366:1809-20.

33. Forner L, Larsen T, Kilian M, Holmstrup P. Incidence of bacteremia after chewing, tooth brushing and scaling in individuals with periodontal inflammation. J Clin Periodontol 2006;33:401-7. 34. Dorn BR, Burks JN, Seifert KN, Progulske-Fox A. Invasion of endothelial and epithelial cells by strains of Porphyromonas gingivalis. FEMS Microbiol Lett 2000;187:139-44.

35. Haraszthy VI, Zambon JJ, Trevisan M, Zeid M, Genco RJ. Identification of periodontal pathogens in atheromatous plaques. J Periodontol 2000;71:1554-60. 36. Haque S, Bruce IN. Therapy insight: systemic lupus erythematosus as a risk factor for cardiovascular disease. Nat Clin Pract Cardiovasc Med 2005;2:423-30.

37. Bacon PA, Stevens RJ, Carruthers DM, Young SP, Kitas GD. Accelerated atherogenesis in autoimmune rheumatic diseases. Autoimmun Rev 2002;1:338-47.

38. Papapanou PN. Periodontal diseases: epidemiology. Ann Periodontol 1996;1: $1-36$.

Copyright (c) 2007 Massachusetts Medical Society. 